\title{
New Model for Measuring Job Quality: Developing an European Intrinsic Job Quality Index (EIJQI)
}

\author{
María Cascales Mira ${ }^{1}$
}

Accepted: 7 January 2021 / Published online: 23 January 2021

(c) The Author(s) 2021

\begin{abstract}
This article deals with the development of a new model for measuring job quality based on the intrinsic components of work, an European Intrinsic Job Quality Index. The objective is measure job quality on the basis of the characteristics inherent to the labour activity itself, and not from its financial rewards. First, we review the existing literature on current measurement models and justify the need for an index of this nature. Secondly, we explain the fundamental methodological decisions adopted for the construction of the index, and present the descriptive model, the indicators that make up each dimension, and the empirical model. Finally, we present the index scores by European Union countries within the framework of institutional theories. In this work, we have used a quantitative methodology, based on social indicator systems, and it has been carried out mainly with data from the European Working Conditions Survey (2015). The fundamental contribution of this article is the construction of a new model for measuring the quality of work, robust, valid and reliable, which will allow us to monitor the intrinsic job quality of the member countries, and thus provide relevant information that contributes to the framework of public policies.
\end{abstract}

Keywords Intrinsic job quality $\cdot$ System of indicators $\cdot$ European countries $\cdot$ Measuring job quality $\cdot$ Comparative analysis $\cdot$ Institutional theories $\cdot$ European working conditions survey

\section{Introduction}

True to its nature, a composite indicator is usually built to 'tell a story'. It is thus ideally suited to identify and bring attention to a possibly latent phenomenon (KucCzarnecka et al. 2020).

The use of composite indicators has increased in the study of human well-being and progress, including a wide range of topics (Becker et al. 2017; Kuc-Czarnecka et al. 2020). One of the fields in which they have had great relevance is in the study of job quality (Ghai 2002; Bonnet et al. 2003; Anker et al. 2003; Bescond et al. 2003; Tangian 2007;

María Cascales Mira

mcascales@us.es

1 Department of Sociology, University of Seville, Seville, Spain 
Davoine et al. 2008a; Leschke and Watt 2008, 2014; Green and Mostafa 2012; Muñoz de Bustillo et al. 2009, 2011a, b; Bericat and Cascales Mira 2019; Boccuzzo and Gianecahini 2015, among others). This is a fundamental dimension of human welfare in modern societies, since working conditions directly affect people's quality of life (Gallie 2009; OECD 2013; Eurofound 2014). Much research has focused on using monetary indicators such as wages to account for the quality of jobs (Hurley et al. 2011; Fernández Macías 2012). However, there is a growing use of models that measure other non-monetary aspects of job performance that are critical to workers' quality of life (Gallie 2009; OECD 2013; Eurofound 2012, 2016). These studies have confirmed the relevance of intrinsic aspects of work such as autonomy, social utility and social relations for the well-being of workers (Eurofound 2014, 2016; Green and Mostafa 2012; Muñoz de Bustillo et al. 2011a; Dahl et al. 2009; Gallie et al. 2012). The characteristics of work considered "intrinsic" are those that focus on the nature of the activity itself, here the reward is derived from the experience of the work itself, while "extrinsic" describes the consequences of the work (salary, promotion, prestige) or the conditions under which it is performed (Seeman 1967). The importance of the intrinsic components of work lies in the fact that the nature of employment conditions has vital consequences for the quality of life of individuals, their capacity and their potential for self-development (Gallie 2009; Kalleberg 2011; Green 2006). As people work for a significant part of their lives, employment can provide them not only with a salary but also with the opportunity to grow, develop new skills and feel socially useful (OECD 2013).

At the institutional level, concern for the quality of employment has been echoed in international organisms since the 1990s. With the changes introduced in the organization of work, the qualitative dimension of employment began to gain importance in Europe (González Begega and Guillén Rodriguez 2009). The focus not only on creating jobs but also on creating better jobs is on the international political agenda, in what has been called the commitment to Decent Work (ILO 1999). In December 2001, the European Commission (EC) adopted a first list of key indicators, which would be included in the 2002 employment guidelines (Laeken European Summit). Since then, the interest in measuring the job quality through indicator systems has spread to various institutions and academia, and is reflected in the growing proliferation of composite indices and indicators aimed at measuring, comparing and monitoring the quality of employment in the Member States. Although the quality of work remains a crucial part of the European policy agenda, some authors consider that there has been a substantial change in its objectives, which are no longer focused on the pursuit of the welfare of European Union citizens and workers, but rather on the increase in terms of productive work and financial attractiveness for job creation (Davoine and Erhel 2007). Along the same lines, Peña-Casas (2009) criticizes the effective implementation of measures to improve the quality of work in Europe, following the proposal of the Laeken indicators and the commitment of the International Labour Organization (ILO) and European countries to the search for Decent Work. Since 2004, a deterioration in the commitment of the community institutions to quality of employment has been perceived (Davoine et al. 2008b). The Kok Report (2004) is an example of the fact that the quantity approach remained the predominant one. Quality has taken a back seat in a scenario of economic slowdown and re-emergence of unemployment. Thus in 2007, the Brussels European Council emphasised improved performance and productivity as incentives for more jobs. In this context of emphasis on economic growth and increased productivity, the introduction of labour-intensive practices, the flexibilisation of forms of hiring and remuneration or the introduction of new forms of management of labour relations by companies (Gallie 2007; Gallie and Paugman 2001; Crompton et al. 2002; Green 2004, 2006; Green et al. 2013; Green and Mcintosh 2001; Gallie 2007; Felstead et al. 
2013) represent new challenges for the quality of jobs in advanced industrialised societies. This is why it is necessary to analyse the quality of the jobs that are being generated. We contribute to this debate by proposing a composite index that exclusively measures the intrinsic aspects of labour activity and which we are going to apply to European countries in comparative analysis: this is an European Intrinsic Job Quality Index (EIJQI). The EIJQI is a new model for measuring job quality, so in this article we will present the process carried out to design, construct, validate and interpret the resulting model by country.

\section{Conceptual Framework: Components of Job Quality}

In general terms, job quality can be considered as those aspects of work activity that contribute to the well-being of individuals (Green 2006; OECD 2013; Muñoz de Bustillo et al. 2011a; Holman 2013). There is no standard or agreed definition in the academic literature; most studies adopt various dimensions that are considered key (European Commission 2001). Thus, the authors agree in defining the quality of employment as a multidimensional concept (Martel and Dupuis 2006; Royuela et al. 2008; Davoine et al. 2008a, b; Dahl et al. 2009; Kalleberg 2000; Kalleberg 2011; Fernández Macías 2012), but not all agree on the dimensions to be analyzed (Findlay et al. 2013; Davoine et al. 2008b). The various approaches have focused their attention on discriminating the relevance of the components that a job must have in order to be considered quality, which shows the lack of agreement on a common definition (The European Parliament's Committee on Employment and Social Affairs 2009). According to Clark (2015), it used to be fairly simple to answer the question, what makes a good job? "Good jobs were those that were well-paid, with perhaps some attention to the length of the work week" (Clark 2015, p 3).

The economic literature has mostly used monetary indicators, based mainly on income level. Although there is a linear relationship between income and satisfaction, the effect on the latter diminishes to some extent with increasing income. This is called the happiness/income paradox (Easterlin 1974). So, there is a correlation between income and job satisfaction, but that correlation is far from perfect. More recent work has emphasized that wages and hours are not sufficient statistics for assessing job quality. Many other aspects of work matter too (Clark 2015). For instance, an increase in wages does not imply an improvement in key aspects for the well-being of the worker such as autonomy in the performance of the activity, the effort made and the intensity of the demands (Green 2006). Some jobs can have a relatively modest salary and still be considered quality jobs in terms of their intrinsic components: being meaningful, allowing the individual to develop his or her potential, being able to exercise autonomy and fostering quality social interactions (Kalleberg 2011; Gallie et al. 2012, 2014). The quality of work, understood from a broader perspective, includes not only financial components but also other employment conditions which have received less attention (Muñoz de Bustillo et al. 2009). In this sense, the sociological perspective has highlighted the importance of non-pecuniary aspects in the analysis of labour quality, placing greater emphasis on aspects related to the characteristics of the job itself, as central components of well-being, as opposed to monetary or extrinsic aspects (Cascales Mira 2010; Kalleberg 2011; Green 2006; Green and Mostafa 2012; Muñoz de Bustillo et al. 2011b; Dahl et al. 2009).

Green (2006) develops the idea that a "good job" is one that allows workers to achieve well-being and reach a range of personal goals, offering the ability to do and be things they value. In terms of motivation, the intrinsic rewards are based on the development of the 
activity itself, from an expressive logic of the self, as opposed to the instrumental logic based on the result that characterizes the extrinsic conditions of work. A job with intrinsic rewards is usually interesting and challenging, one is able to use the skills and abilities, is able to have discretion and learn new things, have autonomy and be recognized for doing a job well done (Kalleberg 1977; Kalleberg and Vaisey 2005).

"Workers who are able to control how and what they do on the job are more likely to get intrinsic rewards from their jobs. Intrinsic rewards are benefits and profits that people obtain from the performance of tasks, as opposed to extrinsic rewards such as money or extra benefits that people obtain from the performance of their work" (Kalleberg 2011, p 7).

Our interest is focused on analyzing the quality of work from its intrinsic components, since we understand this activity not only as a function that provides individuals with material resources to live, but also as the performance that allows the expression of the most anthropological nature of human beings, as an essentially human, meaningful and conscious activity (Muñoz de Bustillo et al. 2011a, b; Erikson 1986). In this line, we show a dimension of work regardless of its monetary value, work becomes a means for the development of the self-expression needs of the individual, not an end to obtain the basic resources for subsistence, which links this activity to the "kingdom of need" (Köhler and Martin Artiles 2009, p 25).

\subsection{Background on Models for Measuring Intrinsic Job Quality}

Intrinsic components of work are increasingly being incorporated into job quality studies (Eurofound 2012b, 2014, 2016; Green and Mostafa 2012; Gallie et al. 2012; Dahl et al. 2009). In this section we examine the background to the use and implementation of intrinsic indicators for measuring job quality.

Initially, the European Commission, through the Laeken indicators, introduces into its model for measuring job quality a dimension called "Characteristics of the work itself", which in turn includes a sub-dimension called "Intrinsic quality of work". The indicators measuring this sub-dimension are "the transitions between employment and unemployment", and "overall satisfaction with current work" (European Commission 2001). The introduction by the European Commission of the intrinsic aspects of job quality has just been an attempt, since the indicators used do not measure anything related to the quality of work itself (Muñoz de Bustillo et al. 2009).

For his part, Gallie (2007) introduces an orientation towards the intrinsic components of work in his study on the preferences of workers in the European Union. In his research, the author measures the orientation towards the intrinsic and extrinsic of workers according to the employment regimes of European countries. To do so, he constructs both dimensions through a factorial analysis, which results in two factors. The intrinsic factor is composed of the indicators: use of initiative, skills and working independently. The extrinsic factor is made up of safety at work and a high salary. According to the results of the research, the intrinsic factor would be more related to higher quality jobs. Likewise, Dahl and colleagues (2009) consider that one of the necessary dimensions that the construction of a model of quality of work should have is constituted by intrinsic characteristics. They establish the important aspects of the quality of the job itself as "Dimensions of the job itself" and they are the following: skills, work intensity, and autonomy and control (Dahl et al. 2009, p 12). Although the authors' work is based on a theoretical proposition and they do not manage to operational the model in a global quality index. 
An important advance in the incorporation of intrinsic indicators to measure the quality of work is carried out by the European Foundation for the Improvement of Living and Working Conditions (Eurofound). The Eurofound team has developed a set of highly detailed indicators to measure the job quality itself. Their European Working Conditions Survey incorporates a battery of items relating to the intrinsic job quality and, through regular reporting, announces the most relevant aspects of job quality. From 2012 these reports already introduce intrinsic job features. Within this framework, Green and Mostafa (2012) develop a report called "Trends in Job Quality in Europe" based on the data from the fifth wave of the EWCS, in which they analyse a series of indicators with the aim of measuring the quality of work in Europe. This report contains an "Index of Intrinsic Work Characteristics" which is composed of the following dimensions: quality of work itself (skills and autonomy), good social environment (social relations in the workplace and negative aspects of the social environment), good physical environment (absence of risk elements), and intensity of work (intensity or effort at work). In the same year, the report "Health and well-being at work: A report based on the fifth European Working Conditions Survey" (2012) introduces the intrinsic characteristics of work, based on the model of Green and Mostafa (2012), as one of the fundamental dimensions of quality at work.

"Quality at work is strongly and positively associated with well-being. Among its many dimensions, intrinsic job quality and job prospects (job security, career advancement, quality of contract) have the greatest impact on well-being" (Eurofound 2012, p 1).

The 2014 report analyses job characteristics by type of occupation and introduces intrinsic job quality factors. In this report the authors link occupation to intrinsic job quality, differentiating job quality by occupational structure. Occupations that require high qualifications are at the highest level of intrinsic job quality and vice versa. The Eurofound 2016 report continues this trend and although it does not produce an overall intrinsic quality index, it does use indices of job quality that look at key intrinsic aspects: physical environment, work intensity, quality of working time, social environment, competences and autonomy at work. These reports are a major contribution to the analysis of the intrinsic aspects that influence the quality of work.

\subsection{Background to the European Intrinsic Job Quality Index}

Our model of intrinsic job quality has been inspired by the references reviewed above for its design, mainly in the model of Green and Mostafa (2012), although it maintains certain differences respect to the final empirical model. The main differences lie in aspects of content and methodology.

Regarding the content, the index by Green and Mostafa places special emphasis on the aspect of training and skills, variables that we have not included in our index. In the case of training, they measure the adequacy between education/training and occupation, which does not determine whether a job is of higher or lower quality, but whether the labour market adjusts the occupational structure to the level of qualification of the workers.

"The items are complemented, first, with an index of the average level of education found in the two-digit occupation in which the work is classified, normalised to the range of $0-1$. This indicator, while not ideal, serves as a proxy for the level of education required in the occupation and is distinct from the education of the individual" (Green and Mostafa 2012, p 22).

In the case of skills, we have not included them as an indicator of labour quality because they are closely related to the amount of autonomy and control that workers have over their 
work (Kalleberg 2011), a dimension that we have included in our index. On the other hand, it includes a series of items such as the use of computers or training in the company, which do not indicate that a job is of quality or at least its measurement is ambiguous: what is the value of using computers?; is it better than working with people?; what kind of training do they receive?; etc. In other words, there are a series of indicators in this dimension that do not strictly measure the intrinsic quality of work, but rather broader aspects of labour quality. Another element that differs from our index is that they only deal with objective items "the objective concept of quality of work focuses on the essential characteristics of jobs that meet the work needs of workers" (Green and Mostafa 2012, p 13) and omits important subjective indicators, such as social utility in the work performed, which has been revealed very important in recent studies of quality of work (Clark 2009; ISSP 2015).

In relation to the methodology, the evidence that the items represent a unified concept or dimension in a group is seen in the score obtained by Cronbach's Alpha, items with low alpha have been discarded (Green and Mostafa 2012, p 24). Cronbach's Alpha is a measure of scale validation, of internal reliability of the data, but it has to be complemented with other analyses to validate the model. Finally, the number of items in each dimension is large, which does not allow for the principle of parsimony so important in the social sciences.

To conclude, despite the growing concern of institutions and authors to measure aspects of labor quality related to the characteristics of the job itself, we have not found an index that exclusively measures these components. The "Intrinsic Characteristics Index" by Green and Mostafa (2012) is the closest empirical reference. Therefore, in order to enrich this field of study, we present a model based on the principle of parsimony, which measures only the intrinsic aspects of work, through the construction of an European Intrinsic Job Quality Index (EIJQI). The EIJQI is not a substitute for other indices of labour quality, its aim is to complement these studies by providing a monitoring tool for the comparison of intrinsic quality between countries and over time. In the following section we present the methodological strategy used for the configuration of the model.

\section{Methodological Strategy: Developing an Intrinsic Job Quality Index}

In this section we will include information on the data source used, the sample, some key methodological features, the measurement instrument, the procedure carried out and the analyses performed.

For the construction of the European Intrinsic Job Quality Index we have used the European Working Conditions Survey (EWCS), wave of 2015. (Eurofound 2015) It has not been difficult to find the necessary variables to carry out our research, since according to Muñoz de Bustillo et al. (2009) it is one of the most complete and exhaustive surveys on working conditions in European countries at present. The sample we have used is the working population of the member countries. It is made up of a total of 27 countries of the European Union.

In relation to some features of the methodological strategy carried out, this has consisted of two differentiated steps. First, we have resorted to the specialized literature that works the models for measuring job quality, since it provides theoretical justifications and empirical evidence of the labor features that have an impact on the well-being of workers (Muñoz de Bustillo et al. 2011a, b). Around this first methodological strategy we raise some previous considerations: on the one hand, the intrinsic job quality covers a diversity of aspects, so for its measurement we have discarded a one-dimensional approach, based 
on the use of a single indicator, and have opted for a multidimensional and multivariate approach, based on the framework of analysis of composite indices.

Although there are pros and cons to the use of composite indices (OECD-JRC 2008; Kuc Czarnecka et al. 2020), this strategy makes it easier for us to measure the reality of complex concepts, based on a series of social indicators located in a previous theoretical framework (Nardo et al. 2005). "A composite index or indicator is a complex descriptive structure, based on a theoretical framework and a conceptual definition, that forms a measurement model empirically operable and capable of quantifying an aspect or phenomenon of social reality" (Bericat and Sánchez Bermejo 2015, p 3).

Some of the most important advantages of its application are:

- Can summarise complex, multi-dimensional realities to support decision-makers

- Are easier to interpret than a battery of many separate indicators

- Can assess the progress of countries over time

- Reduce the visible size of a set of indicators without dropping the underlying information base

- Thus, make it possible to include more information within the existing size limit

- Place issues of country performance and progress at the centre of the policy arena

- Facilitate communication with the general public (i.e. citizens, media) and promote accountability (Kuc-Czarnecka et al. 2020, p 4).

On the other hand, we have opted for a worker-orientated measurement model, that is, the indicators we use must have an intrinsic orientation, they must be based exclusively on the content of the job. Following Green and Mostafa (2012) and Muñoz de Bustillo et al. (2011a, b) we do not include issues related to social security systems, nor quantitative indicators of labour market performance, the EIQJI is based only on the characteristics of jobs that have a direct impact on the well-being of workers. "Any indicator of quality of work must be strictly limited to those aspects of job quality that have a clear and direct impact on workers' wellbeing. The concept of job quality is linked to the characteristics of job performance and its environment, i.e. intrinsic characteristics of the job" (Muñoz de Bustillo et al. 2011b, p 2).

Secondly, in relation to the measuring instrument for the construction of the index we have used an Exploratory Factorial Analysis (EFA), whose purpose is to analyse the relationships of interdependence existing between a set of items, calculating a set of latent variables, called factors, which explain these relationships with a smaller number of dimensions. EFA allows the generation of theoretical model structures and hypotheses that can be empirically contrasted.

The resulting model has been validated using a Confirmatory Factor Analysis (CFA), as this is the appropriate analysis technique to check the robustness of the construct (Escobar 2011; Cea D'Ancona 2002; Bericat 2014, 2018). Furthermore, it is necessary to emphasise the internal reliability of the data, for the study of which Cronbach's Alpha statistician has been applied (Jisu et al. 2006).

The procedure carried out is as follows. Since the sample size is not the same in all countries we have built the model by selecting a random sample of $3 \%$ of the total cases (which means about 1000 cases, implying 991 cases).

In this random sample we have carried out a first exploratory factorial analysis with the variables that, according to the theoretical framework, are appropriate for measuring the intrinsic quality of work. After the exploratory analysis we carried out a confirmatory factor analysis to test the validity and robustness of the model. It was observed that the correlations of two of the items with respect to the factor are not significant. In a following test 
we eliminated those two items and the models were replicated. The factor analysis is again carried out and the parameters are substantially improved.

In a comparative analysis of the intrinsic quality index among the member countries we must check if the model is valid to apply to all countries. Due to the variety of countries in the sample we have carried out metric invariance tests to check that the model fits well in all countries. To run the invariance tests we have grouped the countries according to the typology of employment regimes (Amable 2003; Holman 2013). The typology has been established as follows: the Social-Democratic model includes Denmark, Finland, Sweden and the Netherlands; the Continental model is formed by Germany, France, Austria, Luxembourg and Belgium; the Mediterranean model is made up of Spain, Italy, Greece, Cyprus, Portugal and Malta; the Transition model includes Czech Republic, Poland, Slovakia, Bulgaria, Slovenia, Estonia, Latvia, Hungary, Romania and Lithuania; and finally the Liberal model with the United Kingdom and Ireland. What we have done is a comparative analysis of the index in relation to an initial model (total of the randomly selected sample) and to the 5 groups of countries, to check that the model is valid for all the member countries. We want to know if the model has metric invariance, that is, if it is a valid model that can be used in the different EU countries, if the model behaves in the same way, regardless of the group of countries to which we apply it.

Finally, the EIJQI measurement model is composed of four dimensions and eleven indicators. The dimensions are: the workers' capacity for discretion over their work (Autonomy), the social environment in which the workers interact (Interaction), the effort in terms of psychological demands (Intensity) and the social utility of the work carried out (Meaningful). The indicators that make up each dimension are the following:

Once the indicators used to configure the measurement model have been described, the following section presents the results of the construction of the index in three steps, firstly making the measurement model operational, secondly checking the robustness of the model and thirdly obtaining the final numerical value (Table 1).

\section{Results}

\subsection{First Step: Construction of the EIJQI Measurement Model}

The empirical construction of the index has been carried out through a Common Factor Analysis. The main axis extraction method with varimax rotation has been used. We chose this type of rotation because it minimizes the number of variables with high loads in a factor, thus improving interpretation.

Likewise, we have based our model on Kaiser's rule for the choice of factors, which uses the size of the auto-values as a criterion to decide the number of dimensions that will be present in the factorial solution. Finally, the method used to estimate the factorial scores has been the regression method. The result of the iterations has been a total of four dimensions or latent factors that make up the index. The four factors explain about $69 \%$ of the variance, with a $\mathrm{KMO}^{1}$ of 0.758 .

\footnotetext{
${ }^{1}$ KMO (Kaiser-Meyer-Olkin) is a measure of sample adequacy that contrasts the partial correlations between the variables. The statistic varies between 0 and 1 , small values indicate that factorial analysis is not the most appropriate, since correlations between variables cannot be explained by another variable. According to the literature, a value higher than 0.75 is a good value, so the suitability of the sample to the model's hypothesis is confirmed as acceptable.
} 


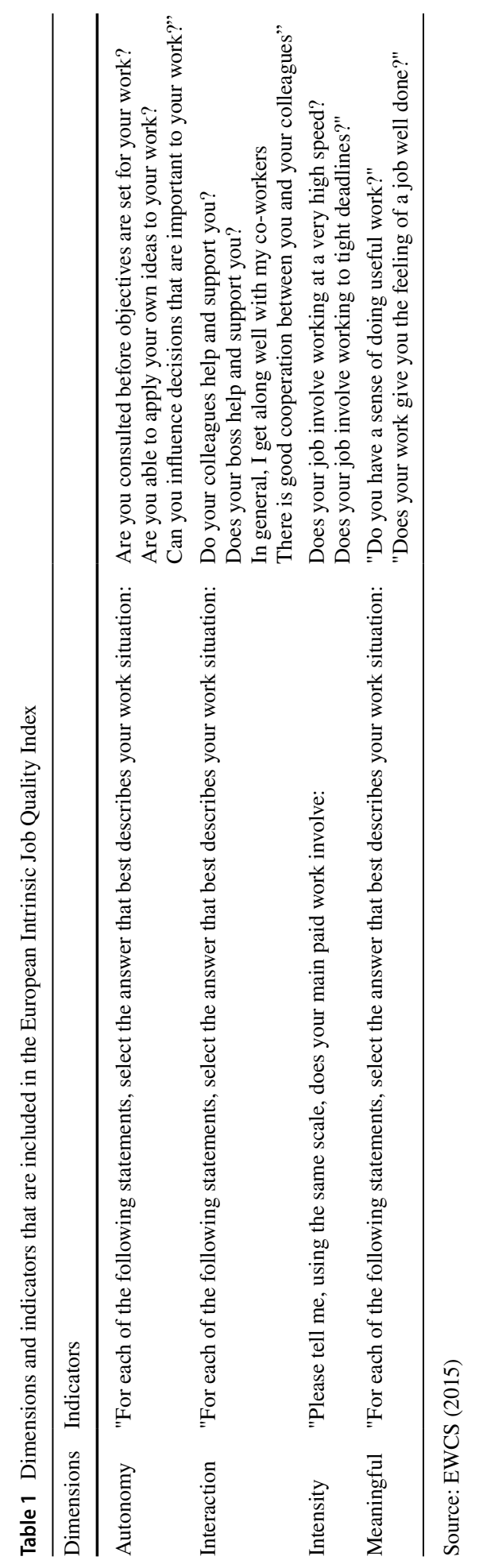


Table 2 European intrinsic job quality index

\begin{tabular}{|c|c|c|c|c|c|c|c|c|c|}
\hline \multirow[t]{2}{*}{ Factor } & \multicolumn{3}{|c|}{ Auto-values } & \multicolumn{3}{|c|}{$\begin{array}{l}\text { Saturations squared from } \\
\text { extraction }\end{array}$} & \multicolumn{3}{|c|}{$\begin{array}{l}\text { Saturations squared from } \\
\text { rotation }\end{array}$} \\
\hline & Total & $\begin{array}{l}\% \text { Vari- } \\
\text { ance }\end{array}$ & $\begin{array}{l}\% \text { Cumula- } \\
\text { tive }\end{array}$ & Total & $\begin{array}{l}\% \text { Vari- } \\
\text { ance }\end{array}$ & $\begin{array}{l}\% \text { Cumula- } \\
\text { tive }\end{array}$ & Total & $\begin{array}{l}\% \text { Vari- } \\
\text { ance }\end{array}$ & $\begin{array}{l}\% \text { Cumu- } \\
\text { lative }\end{array}$ \\
\hline 1 & 3.58 & 32.55 & 32.55 & 3.08 & 28.04 & 28.04 & 1.65 & 14.98 & 14.98 \\
\hline 2 & 1.61 & 14.64 & 47.18 & 1.25 & 11.39 & 39.42 & 1.56 & 14.20 & 29.17 \\
\hline 3 & 1.37 & 12.46 & 59.64 & 0.88 & 7.97 & 47.40 & 1.29 & 11.76 & 40.93 \\
\hline 4 & 1.02 & 9.30 & 68.95 & 0.55 & 5.02 & 52.41 & 1.26 & 11.48 & 52.41 \\
\hline 5 & 0.83 & 7.56 & 76.51 & & & & & & \\
\hline
\end{tabular}

Common factor analysis. Variance explained 4-factor model and 11 indicators

Source: EWCS (2015)

In relation to the variance, Table 2 presents the information about the percentage of total variance explained and the percentage of variance explained by each of the factors of the rotated solution. The set of the four factors explains about $69 \%$ of the total accumulated variance (see percentage in bold). The percentage of variance in each factor is quite homogeneous, it is $14.98 \%$ in the Autonomy factor (1), $14.20 \%$ in the Interaction factor (2), $11.76 \%$ in the Intensity factor (3) and $11.48 \%$ in the Meaningful factor (4). Therefore, all the factors together represent a part of the latent reality that we want to know.

The following table presents the factorial weights of the rotated matrix. If we observe in each column the highest factorial weights (in bold), we can appreciate the intrinsic indicators most associated with each of the four factors. The structure of intrinsic characteristics of each factor facilitates its theoretical interpretation, and allows us to see which aspects constitute the key elements of the latent factors of quality of work. The interpretation procedure is to select the indicators that most intensely saturate each factor, or that have the highest factor weights, in this way we can select the most efficient indicators that represent each dimension of labour quality. "By proceeding in this way we move towards the selection of a model that is both valid and parsimonious" (Bericat 2018, p 111). The factorial structure is as follows:

The indicators relating to "being able to make important decisions at work", "being able to apply one's ideas" and "being consulted before objectives are set" have concentrated the highest factor score around the first factor, which we have labeled "Autonomy". Indicators referring to "good cooperation at work", "good relations with colleagues", "support and help from the boss" and "support and help from colleagues" have concentrated the highest factorial scores around the second factor, which we have labeled as the "Interaction" dimension. The indicators related to the psychological demands "working at high speed" and "working to tight deadlines" have been grouped together to form the latent factor that we have labeled "Intensity". And the indicators relating to "doing useful work" and "doing a job well done" have concentrated on the fourth factor, forming the dimension we have called "Meaningful" (Table 3).

The idea behind the construct of intrinsic job quality is that there is a model that accounts for this reality, so the measurement of the composite indicator must take into account the variance common to all variables and not that which may be due to other factors outside or different from the construct we wish to measure (Bericat 2018). For this purpose we have calculated the communalities, which give an account of the proportion 
Table 3 Common factor analysis

\begin{tabular}{lllll}
\hline Intrinsic indicators & \multicolumn{2}{l}{ Factor scores } & & \\
\cline { 2 - 5 } & F1 Autonomy & F2 Interaction & F3 Intensity & F4 Meaningful \\
\hline To make important decisions & $\mathbf{0 . 7 6 5}$ & 0.105 & 0.006 & 0.147 \\
To apply one's ideas & $\mathbf{0 . 6 6 8}$ & 0.138 & 0.044 & 0.223 \\
Being consulted before objectives are set & $\mathbf{0 . 6 1 9}$ & 0.207 & 0.046 & 0.096 \\
Support and help from colleagues & 0.174 & $\mathbf{0 . 7 5 5}$ & -0.014 & 0.097 \\
Support and help from the boss & 0.310 & $\mathbf{0 . 5 7 7}$ & 0.054 & 0.115 \\
Good relations with colleagues & 0.050 & $\mathbf{0 . 4 7 1}$ & 0.029 & 0.377 \\
Good cooperation at work & 0.085 & $\mathbf{0 . 5 3 7}$ & 0.047 & 0.370 \\
Working at high speed & 0.083 & 0.019 & $\mathbf{0 . 8 0 1}$ & 0.052 \\
Working to tight deadlines & -0.006 & 0.037 & $\mathbf{0 . 7 9 7}$ & 0.041 \\
Doing useful work & 0.212 & 0.172 & 0.044 & $\mathbf{0 . 6 6 6}$ \\
Doing a job well done & 0.214 & 0.210 & 0.057 & $\mathbf{0 . 6 5 8}$
\end{tabular}

Results of the factorial scores. Component matrix

Source: EWCS (2015)

of the variance explained by the common factors in a variable. In our model, the indicators that provide the most information about the factor are working at high speed (0.652), working to tight deadlines $(0.639)$ being able to make important decisions $(0.617)$, having colleagues supporting you (0.609), doing a job well done (0.526) and doing useful work (0.520).

Lastly, in the descriptive analysis it is useful and necessary to emphasize the internal reliability of the data, for which the Cronbach Alpha statistic is analysed. This statistic assumes a model of internal consistency of the data, which estimates the lower limit of the reliability coefficient based on the average of the correlations between the items. The measurement of reliability using Cronbach's Alpha assumes that the items (measured on a Likert scale) measure the same construct and that they are highly correlated. The value of Cronbach's Alfa is 0.722 , indicating high reliability. It can be concluded that the scale is reliable (Jisu et al. 2006). ${ }^{2}$

\subsection{Second Step: Validation of the EIJQI Measurement Model}

The second analysis carried out to test the robustness of the model is a Confirmatory Factor Analysis (CFA). The implementation of this statistical technique has allowed us to correct the deficiencies of the exploratory factor analysis, resulting in a better fit of the model.

To test the validity of the model, we have carried out six Confirmatory Factorial Analyses (CFA). The first one with all the data from the random sample we have selected, which would be the Initial group (it is the model which we are going to compare the rest of the groups to check the metric invariance) and the following analyses with the five groups of countries grouped according to the typology shown.

Regarding the initial model (which is our reference model), the standardized regression coefficients have been statistically significant and the factor loads obtained values greater

\footnotetext{
2 The reliability value in exploratory research should be equal to or greater than 0.6 ; in confirmatory studies it should be between 0.7 and 0.8 .
} 
Table 4 Confirmatory factor analysis. Model fit parameters

\begin{tabular}{lllllll}
\hline & $p$ & PNFI & NFI & TLI & RMSEA (IC 90\%) & CFI \\
\hline Initial model (991 cases) & 0.000 & 0.532 & 0.923 & 0.867 & $0.078(0.076-0.079)$ & 0.925 \\
Social-democratic model (119 cases) & 0.000 & 0.519 & 0.902 & 0.835 & $0.078(0.074-0.083)$ & 0.912 \\
Continental model (212 cases) & 0.000 & 0.521 & 0.906 & 0.839 & $0.081(0.077-0.084)$ & 0.917 \\
Liberal model (66 cases) & 0.000 & 0.538 & 0.917 & 0.864 & $0.078(0.072-0.083)$ & 0.922 \\
Mediterranean model (250 cases) & 0.000 & 0.546 & 0.948 & 0.912 & $0.067(0.064-0.070)$ & 0.928 \\
Transition model (344 cases) & 0.000 & 0.527 & 0.915 & 0.853 & $0.086(0.083-0.088)$ & 0.915 \\
\hline
\end{tabular}

Source: EWCS (2015)

Table 5 Differences between the values of the Bentler Comparative Index (CFI)

\begin{tabular}{lllllll}
\hline Differences between models & Initial & 1 & 2 & 3 & 4 & 5 \\
\hline Intial (991 cases) & 0.00 & & & & & \\
Social-democratic model (119 cases) & 0.01 & 0.00 & & & & \\
Mediterranean model (250 cases) & 0.00 & -0.02 & 0.00 & & & \\
Transition model (344 cases) & 0.01 & 0.00 & 0.01 & 0.00 & 0.00 & 0.00 \\
Continental model (212 cases) & 0.01 & -0.01 & 0.01 & 0.01 & -0.01 & 0.00 \\
Liberal model (66 cases) & 0.00 & -0.01 & 0.01 & -0.01 & & \\
\hline
\end{tabular}

Source: EWCS (2015)

than 0.6. Thus, it can be said that all the indicators satisfactorily saturate with their respective latent variables. The covariance between the factors was not greater than 0.85 and therefore did not present problems of collinearity, which is also evidence of its discriminating validity (Escobedo Portillo et al. 2016). In relation to the fit of the models, Table 4 presents the main parameters for the six analyses carried out.

Due to the variety of countries involved we have carried out metric invariance tests to check that the model fits well in all countries. Following Cheung and Rensvold (2002) we used the CFI parameter as a fitting criterion to compare the different models. A value $\geq 0.9$ indicates an acceptable fit. If we look at the CFI data in the Table 4, the index score is above 0.90 in all groups, indicating an acceptable fit of the initial model and the different groups.

On the other hand, the RMSEA index or approximation mean square error by degree of freedom is recognized as one of the most informative parameters of the models in structural equations (Cea D'Ancona 2002). In general, values in RMSEA less than 0.05 indicate a good fit and values between 0.05 and 0.08 a reasonable fit (Browne and Cudeck 1993).

We have also applied the benchmark advocated by Cheung and Rensvold (2002), to comparatively evaluate the fit of two nested models. To do so, we look at the difference between the values in the Bentler Comparative Index (CFI); if the value of the difference between two nested models is greater than 0.01 in favour of the less restricted model, the model with more restrictions should be rejected. With this approach we will compare the CFI's of the different groups. As shown in Table 5 the difference is $\leq 0.01$ which indicates that we assume metric invariance of the different models with respect to each other and to 
the initial model. This indicates that the model is valid, it works for different groups, which means the model acts in the same way with all countries. The most important part of the table is the comparison of the whole group with each particular group, the nested groups, we see that there are no differences higher than the limit of 0.01 , set by the quoted authors. This fact allows us to infer a metric invariance between the nested models and the total group.

In summary, we can point out that the result generated in the CFA, confirms the suitability of the model composed of the four factors identified and the eleven indicators. The various adjustment indices were adequate, so it can be said that the model proposed for the factor structure of the scale is sustainable.

\subsection{Step Three: Obtaining the Numerical Value of the Index and Final Considerations}

Finally, the data obtained for each factor have been operationalized to obtain the numerical value of the global European Intrinsic Job Quality Index. The global index is calculated as the arithmetic mean of the scores of each factor extracted in the rotated solution of the common factor analysis, which has given a maximum score of 0.99 and a minimum of -2.21 . Values close to the minimum score correspond to lower intrinsic job quality, and as the values approach the maximum value, higher quality is given.

With regard to the weights, each component was weighted equally in the aggregate index. This is because, according to the data seen in Table 2, the variance explained is quite similar among the factors. In addition, following the criteria of several authors (Green and Mostafa 2012; Leschke and Watt 2008; Tangian 2007; Davoine et al. 2008a, b), we have given the same weight to each dimension since otherwise it would be introducing a subjective criterion, changes in the weighting can influence the results (Leschke and Watt 2008).

To conclude, this analytical model will allow us to develop a research framework that measures the intrinsic job quality in the different European countries, in order to present an $\mathrm{X}$-ray of the differences in the more specific area of the non-monetary components of work activity and thus contribute to a field of research that has been little explored. Once the index has been compiled, we move on to present the distribution of intrinsic labour quality by country in the European Union.

\section{The Intrinsic Job Quality in the European Union}

In comparative analysis of job quality, cross-national research has shown that differences in the institutional environment explain divergences in quality of work across countries (Olsen et al. 2010; Gallie 2007; Holman et al. 2009; Holman 2013). The intrinsic job quality also varies across countries, as it is related to a number of institutional factors such as the productive system, the paradigm of work organization, the strength of trade unions or the model of the Welfare State. Research on the approach to employment regimes establishes institutional differences between countries on the basis of their employment policies (Holman 2013; Amable 2003). This research agrees that the greatest labour autonomy is found in the Nordic countries, and the lowest in the Transition and Southern European countries. For its part, the theory of the Varieties of Capitalism (VoC) distinguishes between the liberal market regimes and the coordinated regimes of the Nordic and Continental countries 
(Esser and Olsen 2012; Hall and Soskice 2001; Olsen et al. 2010). According to this approach, there is a relationship between $\mathrm{VoC}$ models and various aspects of job quality, particularly those related to intrinsic characteristics such as autonomy and the possibility of participating in decisions at work (Esser and Olsen 2012). Countries with coordinated regimes would enjoy greater autonomy than countries with liberal regimes. For their part, studies on labor quality in Europe through indicator systems coincide in placing the Nordic countries in the best positions in the labor quality ranking (Leschke et al. 2012; Davoine et al 2008a, b; Tangian 2007; Gallie 2007). Research dealing with the intrinsic job quality, as a more specific area of job quality, also places this group of countries in the highest positions (Gallie 2003; Green and Mostafa 2012), although other countries that were not among them have been incorporated. According to the analysis by Green and Mostafa (2012), the countries with the highest scores are Denmark and the Netherlands, followed by Lithuania and Malta.

What is the distribution of our Intrinsic Job Quality Index in European countries? Table 6 presents the results. The countries with the highest scores are Malta (0.17), Bulgaria (0.16), Ireland (0.13), Netherlands, Denmark and Slovenia (0.12), and Finland (0.9). In line with the previous studies, the Nordic countries remain in a high position in the ranking of job quality, and Malta, Bulgaria and Ireland are added. The countries that have obtained the worst scores are part of the Mediterranean model (Amable 2003) and are Italy $(-0.24)$, Greece $(-0.23)$ and Cyprus $(-0.15)$, of the Continental model Germany $(-0.13)$, and of the Transition model Slovakia $(-0.11)$, Romania $(-0.09)$ and Poland $(-0.07)$.

Looking at the scores of the dimensions that make up the index, the countries with the greatest autonomy at work are Finland (0.29) and Denmark (0.28), followed by Ireland and the UK (0.24), Sweden (0.17) and the Netherlands (0.16). Following the model of the employment regimes, the countries with the least labour autonomy correspond to the countries of the Mediterranean model. According to the results of our index Greece $(-0.50)$, Cyprus $(-0.33)$, Italy $(-0.25)$ and Portugal $(-0.20)$ are the countries with the least autonomy in employment; followed by Germany $(-0.28)$ of the Continental model and Bulgaria $(-0.19)$, as part of the Transition model. Spain, within the model of southern European countries, presents a lower than average score in autonomy $(-0.14)$, workers express having little capacity to make decisions and apply their own ideas. This lack of autonomy may be a symptom of an increase in atypical forms of hiring, based on temporary contracts, which has been occurring in recent decades and which, according to García de Polavieja (2003), is the most common form of entry to the labor market in Spain.

In accordance with the VoC approach, Germany should score high on autonomy, since it belongs to the coordinated market model and instead the score on this dimension has been low. According to Gallie (2007) the variety approach of capitalism, which groups Scandinavian and Continental countries under the coordinated market approach in the same model, is not suitable for assessing the degree of autonomy at work. In his research, the author compares the differences in teamwork and autonomy in five countries (United Kingdom, Germany, Sweden, Denmark and Finland) and shows that Denmark, Finland and Sweden have the highest score in autonomy, but Germany has the lowest score. Germany and the Scandinavian countries present consistent results in terms of skills, but not in terms of control, teamwork and participation (Gallie 2007). The author notes that the greatest differences in autonomy between Scandinavian countries and Germany are due to differences in employment and social welfare regimes. Using Germany as a "critical case", he shows that control and participation follow the pattern of welfare regimes: "the distinctive nature of Scandinavian countries and their differences with Germany point rather to the ability 
Table 6 Intrinsic Job Quality Index and dimensions. Score by European Union countries

\begin{tabular}{|c|c|c|c|c|c|}
\hline EU Countries & EIJQI & Autonomy & Interaction & Intensity & Meaningful \\
\hline Malta & 0.17 & 0.23 & 0.17 & -0.08 & 0.34 \\
\hline Bulgaria & 0.16 & -0.19 & 0.25 & 0.4 & 0.17 \\
\hline Ireland & 0.13 & 0.24 & 0.34 & -0.04 & -0.01 \\
\hline Netherlands & 0.12 & 0.16 & 0.09 & 0.06 & 0.16 \\
\hline Denmark & 0.12 & 0.28 & 0.22 & -0.17 & 0.13 \\
\hline Slovenia & 0.12 & 0.15 & 0.09 & -0.02 & 0.25 \\
\hline Finland & 0.09 & 0.29 & 0.22 & -0.04 & -0.11 \\
\hline Estonia & 0.08 & 0.1 & 0,00 & 0.22 & -0.01 \\
\hline Luxembourg & 0.07 & 0.06 & -0.03 & 0.04 & 0.2 \\
\hline Portugal & 0.06 & -0.20 & 0.19 & 0.1 & 0.17 \\
\hline Latvia & 0.04 & -0.01 & -0.1 & 0.4 & -0.13 \\
\hline UK & 0.03 & 0.24 & 0.17 & -0.09 & -0.2 \\
\hline Austria & 0.03 & 0.10 & -0.09 & -0.01 & 0.11 \\
\hline Belgium & 0.01 & 0.05 & -0.01 & -0.02 & 0.03 \\
\hline Lithuania & 0.01 & -0.03 & 0.03 & 0.28 & -0.23 \\
\hline Czech Republic & 0.00 & 0.11 & -0.2 & 0.22 & -0.14 \\
\hline Sweden & -0.02 & 0.17 & -0.06 & -0.17 & -0.01 \\
\hline Croatia & -0.02 & -0.12 & -0.06 & 0.12 & -0.04 \\
\hline Spain & -0.03 & -0.14 & 0.21 & -0.24 & 0.05 \\
\hline France & -0.04 & -0.04 & -0.23 & 0.1 & 0.03 \\
\hline Hungary & -0.05 & 0.06 & 0.04 & -0.07 & -0.24 \\
\hline Poland & -0.07 & 0,00 & -0.33 & 0.25 & -0.19 \\
\hline Romania & -0.09 & -0.06 & 0.09 & -0.36 & -0.02 \\
\hline Slovakia & -0.11 & -0.11 & -0.3 & 0.31 & -0.35 \\
\hline Germany & -0.13 & -0.28 & -0.32 & 0.02 & 0.06 \\
\hline Cyprus & -0.15 & -0.33 & 0.17 & -0.45 & 0,00 \\
\hline Greece & -0.23 & -0.50 & 0.16 & -0.34 & -0.23 \\
\hline Italy & -0.24 & -0.25 & -0.69 & 0.05 & -0.08 \\
\hline
\end{tabular}

Source: EWCS (2015)

of governments and organized labour to restrict the actions of employers in the interest of improving the quality of employees' working lives" (Gallie 2007, 100).

In relation to the intensity dimension, the countries whose workers are exposed to a greater intensity in the work correspond to the regimes of the South of Europe, Cyprus $(-0.45)$, Greece $(-0.36)$, and Spain $(-0.24)$ and of Transition Romania $(-0.36)$. These countries are characterised by a growing service sector. This sector is one of the most polarized, and is divided into high and low quality jobs (Kalleberg 2011; García de Polavieja 2003). The former are associated with high qualification jobs, the latter are associated with low qualification jobs related to catering and sales services, where high intensity work is performed. The countries with lower labour intensity correspond to the Transition model: Bulgaria and Latvia (0.40), Lithuania (0.28) and Czech Republic (0.22).

We would like to underline that the countries of the Mediterranean model are the ones that score the lowest in autonomy and the highest in intensity. This combination can have negative effects on the quality of life and health of workers. According to the 
Demand-Control model developed by Karasek (1979), the negative effects on workers' well-being derive from the joint effect of the demands (intensity) of a work situation, and the range of autonomy in the decisions made by workers to deal with those demands. The combination of high intensity and low autonomy generates a high strain worker model.

In the Interaction dimension, Ireland $(0.34)$ is the country where workers establish the highest quality network of relationships in the working environment. It is followed by Bulgaria (0.25), Denmark and Finland (0.22) and Spain (0.21). In the Scandinavian countries, teamwork and social support of colleagues is strengthened. In Spain, social interactions are an important component in labour relations. This may be due to its system of electoral hearings, with a high participation by workers, which reinforces relations between co-workers and between bosses or supervisors. In contrast, countries with lower quality of labour relations are Italy (-0.69), Poland (-0.33), and Slovakia (-0.30). According to Holman (2013), the employment regime in transition countries is characterized by relatively low state intervention in the regulation of working conditions, and a relatively weak trade union movement, which may have an impact on less unity among workers.

Finally, doing useful and well-done work, the meaning given to the development of labour activity, scores high in Malta, Slovenia, Luxembourg and Bulgaria. On the other hand, in other recently incorporated countries such as Slovakia, Hungary, Lithuania and Greece, there is a low perception of meaning in the work carried out.

To conclude, in general terms the Scandinavian countries located in the Nordic model are at the top in terms of quality of work (Leschke et al. 2012; Davoine et al 2008a, b; Tangian 2007; Gallie 2007), also in relation to the intrinsic job quality, although other countries such as Malta, Ireland and Bulgaria have joined this ranking. The Scandinavian countries have taken seriously the quality of working conditions of their population, both in the organization of work, as in the participation of unions, their policies on labor, their legislation, and the characteristics of their Welfare State (Gallie 2003). In contrast, the countries that score lowest in the index are the countries of the southern European model, and Germany of the continental model, which is a "critical case" within the countries of coordinated economies (Gallie 2007).

Finally, the countries of the Nordic model are those that have the greatest autonomy, along with the United Kingdom and Ireland, pioneering countries in promoting the "Humanization of Work" movements, which emphasize the importance of autonomy, discretion and work in autonomous teams. The workers with the least autonomy belong to the countries of the Southern European model. These countries are in turn the most labourintensive, which can have negative repercussions on the health and quality of life of workers, following Karasek's model (1979). Germany stands out within the model of the coordinated economy, which scores low in both the overall intrinsic quality and the autonomy and interaction dimensions.

\section{Conclusions}

In this work we have built a new model for measuring job quality, with data from the European Working Conditions Survey (2015). It is an European Intrinsic Job Quality Index. The index we have obtained provides, as with other composite indices of job quality, a quantitative measurement of the quality of work in jobs, except that this model starts from a worker-oriented approach to the intrinsic aspects of work. On the other hand, since it is a multidimensional construct, it is richer, more robust and informative 
than one-dimensional measurement models, such as the one based on the analysis of quality through general job satisfaction (Muñoz de Bustillo et al. 2011a, b). This is because the final EIJQI scores are not derived from a categorical or ordinal scale with five levels of response (as in the classical satisfaction scale), but rather are metric scores on a continuous scale ranging from -2.21 , minimum quality, to 0.99 , maximum quality, which allows for greater richness in their measurement and interpretation. In addition, the "hierarchical" structure of the composite index allows us to examine the different levels of information: firstly, the overall score of the composite index gives us information on the overall intrinsic quality; secondly, the factorial scores of each of the four dimensions give us specific information on the quality of workers in each of the key aspects; and finally, the indicators used in the empirical construction of the index are the source of more detailed information on the main intrinsic conditions of work.

Once the index has been constructed, we have applied it to the countries of the European Union in order to determine whether there are differences in the intrinsic job quality, within the framework of institutional theories. The results show that the countries of the Nordic model are the ones that score better in intrinsic quality, following the trend of previous studies, but Malta, Bulgaria and Ireland have been incorporated and are in the first positions. The studies of job quality, which include less specific aspects of the job, present very similar scores by country, but when applying our model (which includes only intrinsic aspects of work) the quality scores vary and new countries appear in the first positions of the ranking.

The countries that score worst in our ranking are those that belong to the Southern European model (Italy, Greece and Cyprus), recently incorporated (Slovakia) and within the coordinated model Germany as a "critical case" (Gallie 2007). The countries that have more autonomy are the Nordic countries, United Kingdom and Ireland, countries that bet on the capacity and autonomy of workers. These countries in turn present scores close to the average in intensity, which combined with high control generates a type of active worker, with positive repercussions on their labor quality (Karasek 1979). In contrast, the countries belonging to the Southern European model are those that present lower scores in autonomy and in turn higher scores in intensity, which can generate high strain worker models.

Lastly, variations in job quality between countries are influenced by institutional differences (Gallie 2003, 2007; Olsen et al. 2010; Holman 2013; Esser and Olsen 2012; Holman et al. 2009). According to divergence theories (Olsen et al. 2010), different institutional regimes mean that disparities in job quality between countries are sustained over time. In contrast, convergence theories hold that countries converge on similar employment trends due to factors such as technology, globalization or deregulation, which minimize the effects of the institutional context. As Olsen and colleagues (2010) point out, the main trend observed in terms of convergence is an increase in job insecurity and labour intensity. In this sense, the quality of work is deteriorating in all countries and the differences between countries have narrowed over time. Institutional features may explain some differences in job quality across countries, although they cannot explain differences in many of the intrinsic aspects (Olsen et al. 2010). This is a field that has not yet been fully explored, and requires research that contributes to understanding the configuration of the components inherent to the performance of work activity, regardless of its pecuniary components, and its impact on the quality of workers. We therefore hope that this proposed new measurement model will help to broaden the framework of future research on differences in the intrinsic job quality between 
European countries, something that ultimately concerns public policies to improve working conditions.

Open Access This article is licensed under a Creative Commons Attribution 4.0 International License, which permits use, sharing, adaptation, distribution and reproduction in any medium or format, as long as you give appropriate credit to the original author(s) and the source, provide a link to the Creative Commons licence, and indicate if changes were made. The images or other third party material in this article are included in the article's Creative Commons licence, unless indicated otherwise in a credit line to the material. If material is not included in the article's Creative Commons licence and your intended use is not permitted by statutory regulation or exceeds the permitted use, you will need to obtain permission directly from the copyright holder. To view a copy of this licence, visit http://creativecommons.org/licenses/by/4.0/.

\section{References}

Amable, B. (2003). The Diversity of Modern Capitalism. Oxford University Press. https://doi. org/10.1093/019926113X.001.0001.

Anker, R., Chernyshev, I., Egger, P., Mehran, F., \& Ritter, J. A. (2003). Measuring decent work with statistical indicators. International Labour Review, 142(2), 147-178. https://doi.org/10.1111/j.1564913X.2003.tb00257.X.

Becker, W., Paruolo, P., Saisana, M., \& Saltelli, A. (2017). Weights and importance in composite indicators: Mind the gap, In R. Ghanem, D. Higdon, H. Owhadi (Eds.), Handbook of Uncertainty Quantification, pp. 1187-1216, Berlin: Springer. https://doi.org/10.1007/978-3-319-12385-1.

Bericat, E. (2014). The Socioemotional Well-Being Index (SEWBI): Theoretical Framework and Empirical Operationalisation. Social Indicators Research, 119(2), 599-626. https://doi.org/10.1007/s1120 5-013-0528-z.

Bericat, E. (2018). Excluidos de la felicidad: La estratificación social del bienestar emocional en España. Centro de Investigaciones Sociológicas.

Bericat, E., \& Cascales Mira, M. (2019). Job Quality. In The quality of European societies: A compilation of composite indicators (pp. 167-186). Springer.

Bericat, E., \& Sánchez Bermejo, E. (2015). Structural gender equality in Europe and its evolution over the first decade of the twentyfirst century. Social Indicators Research, 127(1), 55-81. https://doi. org/10.1007/s11205-015-0949-y.

Bescond, D., Châtaignier, A., \& Mehran, F. (2003). Seven indicators to measure decent work: An international comparison. International Labour Review, 142(2), 179-212. https://doi.org/10.1111/j.1564913X.2003.tb00258.X.

Boccuzzo, G., \& Gianecchini, M. (2015). Measuring Young graduates' job quality through a composite indicator. Social Indicators Research, 122, 453-478.

Bonnet, F., Figueiredo, J. B., \& Standing, G. (2003). A family of decent work indexes. International Labour Review, 142(2), 213-238. https://doi.org/10.1111/j.1564-913X.2003.tb00259.x.

Browne, M. W. \& Cudeck, R. (1993). Alternative ways of assessing model fit. En K. A. Bollen y J. S. Long (Eds.), Testing structural equation models (pp. 136-162). Newbury Park, CA: Sage.

Cascales Mira, M. (2010). Análisis de la satisfacción laboral en España. Documentos de trabajo (Centro de Estudios Andaluces ), 5, 1-41.

Cea D’Ancona Ma, A. (2002). Análisis multivariable teoría y práctica de la investigación social. Madrid: Síntesis.

Cheung \& Rensvold. (2002). Evaluating goodness-of-fit indexes for testing measurement invariance. Structural equation Modeling, 9(2), 233-255.

Clark, A. E. (2009). Work, jobs and well-being across the Millennium (Working Paper No 2009-02; p. 44). Paris School of Economics and IZA.

Clark, A. (2015). What makes a good job? Job quality and job satisfaction. IZA World of Labor. https://doi. org/10.15185/izawol.215

Crompton, R., Gallie, D., \& Purcell, K. (2002). Work, Economic Restructuring \& Social Regulation. Changing forms of employment: In Organisations, skills and gender. London. Routledge. https://doi. org/10.4324/9780203202135

Dahl, S. -A., Nesheim, T., \& Olsen, K. M. (2009). Quality of work: Concept and measurement. SSRN Electronic Journal, 5, 28. 
Davoine, L., \& Erhel, C. (2007). La qualité de 1'emploi en Europe : une approche comparative et dynamique. Economie et Statistique., 410, 47-69.

Davoine, L., Erhel, C., \& Guergoat-Lariviere, M. (2008a). Monitoring quality in work: European Employment Strategy indicators and beyond. International Labour Review, 147(2-3), 163-198. https://doi. org/10.1111/j.1564-913X.2008.00030.x.

Davoine, L., Erhel, C., \& Guergoat-Lariviere, M. (2008b). A Taxonomy of European Labour Markets Using Quality Indicators. HAL, University Paris1 Pantheon-Sorbonne (Post-Print and Working Papers), 118.

Easterlin, R. A. (1974). Does economic growth improve the human lot? some empirical evidence. En Nations and Households in Economic Growth (pp. 89-125). https://doi.org/10.1016/B978-0-12205050-3.50008-7

European Commission. (2001). Employment in Europe 2001: Recent trends and prospects. Luxembourg: Office for Official Publications of the European Communities.

Erikson, K. (1986). On work and alienation. American Sociological Review, 51(1), 1. https://doi. org/10.2307/2095474.

Escobar, M. (2011). La calidad democrática. Una propuesta para su medición por expertos. Reis: Revista española de investigaciones sociológicas, 133, 59-80.

Escobedo Portillo, M. T., Hernández Gómez, J. A., Estebané Ortega, V., \& Martínez Moreno, G. (2016). Modelos de ecuaciones estructurales: Características, fases, construcción, aplicación y resultados. Ciencia \& trabajo, 18(55), 16-22.

Esser, I., \& Olsen, K. M. (2012). Perceived job quality: autonomy and job security within a multi-level framework. European Sociological Review, 28(4), 443-454. https://doi.org/10.1093/esr/jcr009.

Eurofound. (2012a). Health and Well-being at Work: A Report Based on the Fifth European Working Conditions Survey. Dublin: Eurofound.

Eurofound (Ed.). (2012b). Trends in job quality in Europe: A report based on the fifth European Working Conditions Survey. Luxembourg: Publ. Off. of the Europ. Union [u.a.].

Eurofound. (2014). Occupational profiles in working conditions: Identification of groups with multiple disadvantages (p. 74). Dublin: Eurofound.

Eurofound. (2015). Sixth European Working Conditions Survey. Luxembourg: Publications Office of the European Union.

Eurofound. (2016). Sixth European Working Conditions Survey - Overview Report (p. 165). Luxembourg: Publications Office of the European Union.

Felstead, A., Gallie, D., Green, F., \& Inanc, H. (2013). Work Intensification in Britain: First Findings from the Skills and Employment Survey 2012 (p. 6). London: Centre for Learning and Life Chances in Knowledge Economies and Societies.

Fernández-Macías, E. (2012). Job Polarization in Europe? Changes in the employment structure and job quality, 1995-2007. Work and Occupations, 39(2), 157-182. https://doi.org/10.1177/0730888411 427078.

Findlay, P., Kalleberg, A. L., \& Warhurst, C. (2013). The challenge of job quality. Human Relations, $66(4), 441-451$.

Gallie, D. (2003). The quality of working life: Is Scandinavia different? European Sociological Review, $19(1), 61-79$.

Gallie, D. (2007). Welfare regimes, employment systems and job preference orientations. European Sociological Review, 23(3), 279-293.

Gallie, D. (2009). Employment Regimes and the Quality of Work. Oxford University Press.

Gallie, D., \& Paugman, S. (2001). Welfare Regimes and the Experience of Unemployment in Europe. Cambridge University Press., 30(2), 361-391.

Gallie, D., Felstead, A., \& Green, F. (2012). Job preferences and the intrinsic quality of work: The changing attitudes of British employees 1992-2006. Work, Employment and Society, 26(5), 806821. https://doi.org/10.1177/095001701245163.

Gallie, D., Felstead, A., Green, F., \& Inanc, H. (2014). The quality of work in Britain over the economic crisis. International Review of Sociology, 24(2), 207-224. https://doi.org/10.1080/03906 701.2014.933023.

García de Polavieja, J. (2003). Estables y precarios: Desregularización laboral y estratificación social en España (1. ed). Madrid: Centro de Investigaciones Sociológicas : Siglo Veintinuno de España Editores.

Ghai, D. P. (2002). Decent work: Concepts, models and indicators. Geneva: International Institute for Labour Studies.

González Begega, S., \& Guillén Rodríguez, A. M. (2009). La calidad del empleo en la Unión Europea. Revista del Ministerio de Trabajo e Inmigración: Debate político y construcción de indicadores.

Green, F. (2004). Why has work effort become more intense? Industrial Relations, 43(4), 709-741. https ://doi.org/10.1111/j.0019-8676.2004.00359.x. 
Green, F. (2006). Demanding work: The paradox of job quality in the affluent economy (Second printing, and first paperback printing) (Second printing, and first paperback printing). Princeton, New Jersey: Princeton University Press.

Green, F \& Mcintosh, S. (2001). The intensification of work in Europe, en Labour Economics, no 8, p. 291-308

Green, F., \& Mostafa, T. (2012). Job quality indices for Europe. A Report Based On The Fifth European Working Conditions Survey. (p. 69). London: Llakes Centre, Institute of Education.

Green, F., Mostafa, T., Parent-Thirion, A., Vermeylen, G., van Houten, G., Biletta, I., \& Lyly-Yrjanainen, M. (2013). Is job quality becoming more unequal? ILR Review, 66(4), 753-784. https://doi. org/10.1177/001979391306600402.

Hall, P. A., \& Soskice, D. W. (2001). An Introduction to Varieties of Capitalism. In: En D. W. Soskice (Ed.), Varieties of capitalism: The institutional foundations of comparative advantage (pp. 1-70). Oxford [England] ; New York: Oxford Universit Press.

Holman, D. (2013). Job types and job quality in Europe. Human Relations, 66(4), 475-502. https://doi. org/10.1177/0018726712456407.

Holman, D., Frenkel, S., Sørensen, O., \& Wood, S. (2009). Work design variation and outcomes in call centers. Strategic choice and institutional explanations. Industrial and Labor Relations Review, 62, 510-532.

Hurley, J., Storrie, D. W., \& Jungblut, J.-M. (2011). Shifts in the job structure in Europe during the great recession. Luxembourg: Publications Office of the European Union.

Jisu, H., Delorme, D. E., \& Reid, L. N. (2006). Perceived third-person effects and consumer attitudes on prevetting and banning DTC advertising. Journal of Consumer Affairs, 40(1), 90-116.

Kalleberg, A. L. (1977). Work values and job rewards: A theory of job satisfaction. American Sociological Review, 42(1), 124.

Kalleberg, A. L. (2000). Nonstandard employment relations: part-time, temporary and contract work. Annual Review of Sociology, 2, 341-365.

Kalleberg, A. L. (2011). Good jobs, bad jobs: The rise of polarized and precarious employment systems in the United States, 1970s to 2000s. New York: Russell Sage Foundation.

Kalleberg, A. L., \& Vaisey, S. (2005). Pathways to a good job: Perceived work quality among the Machinists in North America. British Journal of Industrial Relations, 43(3), 431-454. https://doi. org/10.1111/j.1467-8543.2005.00363.x.

Kalleberg, A. L., Reskin, B. F., \& Hudson, K. (2000). Bad jobs in America: Standard and nonstandard employment relations and job quality in the United States. American Sociological Review, 65(2), $256-278$.

Karasek, R. (1979). Job demands, job decision latitude, and mental strain: implications for job redesign. Administrative Science Quarterly, 24(2), 285. https://doi.org/10.2307/2392498.

Köhler, H.-D., \& Martín Artiles, A. (2009). Manual de la sociología del trabajo y de las relaciones laborales. Delta.

Kok, W. (2004). Jobs, jobs, jobs: Creating more employment in Europe: report of the Employment Taskforce chaired by Wim Kok, November 2003. Luxembourg: Office for Official Publications of the EC.

Kuc-Czarnecka, M., Lo Plano, S., \& Saltelli, A. (2020). Quantitative storytelling in the making of a composite indicator. Social Indicators Research. https://doi.org/10.1007/s11205-020-02276-0.

Leschke, J., \& Watt, A. (2008). Putting a number on job quality? Constructing a European Job Quality Index (p. 23). Brussels: ETUI.

Leschke, J., \& Watt, A. (2014). Challenges in constructing a multi-dimensional European Job Quality Index. Social Indicators Research, 118(1), 1-31. https://doi.org/10.1007/s11205-013-0405-9.

Leschke, J., Watt, A., \& Finn, M. E. (2012). Job quality in the crisis—an update of the Job Quality Index (JQI). SSRN Electronic Journal. https://doi.org/10.2139/ssrn.2208374.

Martel, J.-P., \& Dupuis, G. (2006). Quality of work life: Theoretical and methodological problems, and presentation of a new model and measuring instrument. Social Indicators Research, 77(2), 333368. https://doi.org/10.1007/s11205-004-5368-4.

Muñoz de Bustillo Llorente, R., Fernández Macías, E., Antón, J. I., \& Esteve, F. (2009). Indicators of job quality in the European Union. European Parliament's Committee on Employment and Social Affairs.

Muñoz de Bustillo, M., Llorente, R., Fernández Macías, E., Antón Pérez, J. I., \& Esteve Mora, F. (Eds.). (2011a). Measuring more than money: The social economics of job quality. Cheltenham, U.K.; Northampton. Mass: Edward Elgar.

Muñoz de Bustillo, M., Llorente, R., Fernández Macías, E., Esteve Mora, F., \& Antón Pérez, J. I. (2011b). E pluribus unum? A critical survey of job quality indicators. Socio-Economic Review, 9(3), 447-475. https://doi.org/10.1093/ser/mwr005. 
Nardo, M. et al. (2005). Handbook on Constructing Composite Indicators: Methodology and User Guide. OECD Statistics Working Papers, 2005/03, OECD Publishing. https://doi.org/10.1787/5334118150 16

OECD. (2013). How's life? 2013: measuring well-being. Paris: OCDE.

OECD-JRC (2008). Handbook on constructing composite indicators: Methodology and user guide, OECD Statistics working paper JT00188147, STD/DOC(2005)3.

Olsen, K. M., Kalleberg, A. L., \& Nesheim, T. (2010). Perceived job quality in the United States, Great Britain, Norway and West Germany, 1989-2005. European Journal of Industrial Relations, 16(3), 221-240. https://doi.org/10.1177/0959680110375133.

Peña-Casas, R. (2009). More and better jobs: Conceptual framework and monitoring indicators of quality of work and employment in the EU Policy Arena. SSRN Electronic Journal, 49, . https://doi.org/10.2139/ ssrn.1489925.

Royuela, V., López-Tamayo, J., \& Suriñach, J. (2008). The institutional vs. the academic definition of the quality of work life. What is the focus of the European Commission? Social Indicators Research, $86(3), 401-415$.

Seeman, M. (1967). On the personal consequences of alienation in work. American Sociological Review, 32(2), 273. https://doi.org/10.2307/2091817.

Tangian, A. (2007). Analysis of the third European survey on working conditions with composite indicators. European Journal of Operational Research, 181(1), 468-499. https://doi.org/10.1016/j. ejor.2006.05.038.

Publisher's Note Springer Nature remains neutral with regard to jurisdictional claims in published maps and institutional affiliations. 